Nephron 1991;57:1

\title{
Editors' Announcement
}

We are happy to announce the introduction of two innovations into Nephron 's pages in the coming volumes.

Grand Rounds. This section will be under the editorship of Professor Dr. Eberhardt Ritz of Heidelberg and will include grand rounds from various leading European centers of nephrology. We look forward to an exciting section presenting the up-to-date nephrological handling of problems in a stimulating format which will be a valuable learning experience unparalleled in the available nephrological literature. Professor Dr. Ritz will be given a free hand in the choice of subjects and centers of excellence which will be the sites of the grand rounds, and we expect to publish one each volume initially, i.e. three per year.

Controversies in Nephrology. It is now 20 years since we introduced controversies to the page of Nephron, and the idea was contagious and caught on particularly in the US long after we discontinued the series. We will shortly introduce Vignettes of Controversies in Nephrology in the coming volumes of Nephron . The series will be under the editorship of Professor Man Oh of the State University of New York at Brooklyn whose brilliant, iconoclastic and stimulating articles will blow away many cobwebs from the readers' minds as he has done from ours. The person representative of the opposing view will be invited to state his views in juxtaposition to those of Professor Oh or his colleagues. We know that the readers will enjoy this heuristic exercise and look forward to publishing such vignettes once per volume initially. G.M. Berlyne, Brooklin, N.Y. S. Giovannetti, Pisa 